\title{
Aspectos morfológicos de frutos, sementes e desenvolvimento de plântulas e plantas jovens de Unonopsis lindmanii Fries (Annonaceae)
}

\author{
Joanice Lube Battilani ${ }^{1,4}$, Etenaldo Felipe Santiago² e Andréa Lúcia Teixeira de Souza ${ }^{3}$
}

Recebido em 23/01/2006. Aceito em 15/03/2007

\begin{abstract}
RESUMO - (Aspectos morfológicos de frutos, sementes e desenvolvimento de plântulas e plantas jovens de Unonopsis lindmanii Fries (Annonaceae)). Unonopsis lindmanii é uma arvoreta, perene, restrita às formações ciliares do Brasil Central. Este estudo descreve os aspectos morfológicos dos frutos, sementes e desenvolvimento das formas juvenis da espécie. Os frutos são apocárpicos, múltiplos, livres entre si, carnosos, indeiscentes e as sementes possuem forma discóide, coloração marrom escura, tegumento ornamentado de aspecto rugoso. A germinação é lenta, irregular e muito baixa em câmara de germinação (3\%) e alta em viveiro de mudas (70\%) sugerindo fotoperiodismo positivo. A plântula é do tipo criptocotiledonar-epígea. As plantas jovens apresentam folhas simples, alternas, com pecíolos curtos, simétricas, membranáceas de forma elíptica. O padrão de venação é do tipo camptódromo-broquidódromo. Estes resultados permitem identificação da espécie no campo, o que pode auxiliar em estudos de descrições de comunidades e por serem dispersas por aves, consiste em excelente opção para utilização em projetos de restauração de áreas degradadas.
\end{abstract}

Palavras-chave: Unonopsis lindmanii, frutos, sementes, germinação, padrão de venação

\begin{abstract}
Morphological aspects of fruits, seeds, and seedling and sapling development of Unonopsis lindmanii Fries (Annonaceae)). Unonopsis lindmanii is a small tree restricted to riparian forests in Central Brazil. Here we describe the morphological characteristics of the fruits and seeds, and the development of seedlings. The multiple, indehiscent fruits are apocarpous, unattached to one another, with a fleshy pericarp, and the seeds are darkish brown and discoid in shape, with an ornamented, rugose tegument. Germination is slow and irregular, and rates are very low in the germination chamber (3\%). They are high in the greenhouse (70\%) suggesting positive photoperiodism. Initial seedling morphology is cryptocotyledonar-epigeous. Saplings have simple, alternate leaves with short petioles, and are symmetric, membranous, and elliptical. The venation pattern is of the brochidodrome-camptodrome type. These results help to identify the species in the field, and may also contribute to community description studies. Because it is dispersed by birds, this species is an excellent option for use in restoration projects of degraded areas.
\end{abstract}

Key words: Unonopsis lindmanii, fruits, seeds, germination, venation pattern

\section{Introdução}

A família Annonaceae A.L. Juss., possui distribuição pantropical e compreende cerca de 120 gêneros que englobam 1.100 espécies em média, sendo que no Brasil, estão registrados 29 gêneros e aproximadamente 260 espécies (Barroso et al. 2002). A família é constituída por árvores, arbustos, e raramente por arbustos escandentes (Pontes et al. 2004). No Cerrado é representada por diversos gêneros e espécies, sendo muitas cultivadas pelos deliciosos frutos, como Annona coriaceae Mart., Annona crassiflora Mart. e Rollinia emarginata Schl. (Silva et al. 2001) e outras pelo potencial ornamental, como Xylopia aromatica (Lam.) Mart. (Silva Júnior et al. 2005).

Unonopsis lindmanii Fries, vulgarmente conhecida como pindaíba-preta é uma arvoreta de 2 a 7 metros de altura, perene, característica de subbosque (Pott \& Pott 1994). Apresenta distribuição ecogeográfica restrita ao Brasil Central (Oliveira Filho \& Ratter 2000), associada às formações ciliares, com forte preferência por solos mais úmidos (Romagnolo \& Souza 2000; Felfili et al. 2001). Quanto à categoria sucessional é classificada como clímax, tolerante à sombra por Toniato \& Oliveira Filho (2004). O constante processo de fragmentação e alteração da

\footnotetext{
1 Programa de Pós-Graduação em Ecologia e Conservação, Universidade Federal de Mato Grosso do Sul, Campo Grande, MS, Brasil; Superintendência Estadual do Ibama, MS, Rua 13 de maio 2967, 79002-351 Campo Grande, MS, Brasil

2 Universidade Estadual de Mato Grosso do Sul, Laboratório de Ecologia, GASLAB, C. Postal 351, 79804-970 Dourados, MS, Brasil

3 Universidade Federal de Mato Grosso do Sul, Departamento de Biologia, CCBS, C. Postal 549, 79070-900 Campo Grande, MS, Brasil

4 Autora para correspondência: joanice@econet.com.br
} 
paisagem natural, tem reduzido drasticamente a cobertura florestal em diversas regiões do Brasil, colocando em risco e levando à extinção diversas espécies vegetais (Tabarelli et al. 1999). Nesse sentido, o conhecimento biológico das espécies nativas é fundamental na implantação de projetos de manejo florestal, conservação e reconstituição desses ecossistemas (Ferreira et al. 2001; Cunha \& Ferreira 2003; Melo et al. 2004).

A análise tradicional de órgãos vegetativos e florais muitas vezes é insuficiente para solucionar problemas taxonômicos e filogenéticos, sendo necessário o estudo de frutos, sementes, plântulas e plantas jovens com propósitos taxonômicos, filogenéticos ou ecológicos e, também como contribuição ao conhecimento das espécies (Oliveira 2001). O estudo do padrão de venação das folhas permite comparações entre espécies do mesmo gênero (Cardoso \& Sajo 2004).

No Estado de Mato Grosso do Sul, U. lindmanii tem ocorrência natural nas formações ciliares (Pott \& Pott 2003). Em trecho da mata ciliar do rio da Prata, no município de Jardim, MS, destaca-se pela elevada dominância e importância ecológica (Battilani et al. 2005). Este estudo teve como objetivos descrever os aspectos morfológicos dos frutos, sementes e desenvolvimento das plântulas e plantas jovens de $U$. lindmanii e verificar o padrão de venação das folhas jovens com o propósito de contribuir na identificação da espécie em estudos de descrições de comunidades vegetais e fornecer subsídios para posteriores estudos em projetos de recomposição vegetal.

\section{Material e métodos}

As coletas de material botânico foram realizadas mensalmente entre julho de 2000 a agosto de 2001, num trecho da mata ciliar do Rio da Prata, na fazenda Nossa Senhora Aparecida $\left(56^{\circ} 21^{\prime} \mathrm{W} ; 2^{\circ} 25^{\prime} \mathrm{S}\right)$, município de Jardim, MS. Os frutos maduros foram coletados diretamente das árvores, com auxílio de podão, ao longo de uma trilha de cerca de dois quilômetros, paralela ao rio. O material foi triado e examinado no Laboratório de Biologia Vegetal da Universidade Estadual de Mato Grosso do Sul, Unidade de Ensino de Jardim. Os ramos providos de flores e os frutos imaturos foram examinados a fresco e fixados em FAA 70\% (Johansen 1940) para estudos posteriores.

O processo de beneficiamento das sementes foi realizado manualmente, com auxílio de peneira e água corrente. Após, as sementes foram colocadas para secar em temperatura ambiente. O número de sementes por fruto e a biometria dos frutos e sementes foi estimada em amostras aleatórias de 100 unidades. As dimensões, comprimento ( $\mathrm{mm})$, largura $(\mathrm{mm})$ e massa $(\mathrm{g})$ foram verificadas para frutos e sementes com auxílio de paquímetro digital (Starret) (precisão de 0,01 mm) e balança analítica (Micronal B600) (precisão $0,01 \mathrm{~g}$ ).

As sementes utilizadas para os estudos pósseminais foram desinfectadas em hipoclorito de sódio a $20 \%$ (durante 30 minutos) e em seguida, lavadas em água corrente. Cinco amostras de 10 sementes cada, foram colocadas para germinar, sem tratamento prégerminativo, em placas de petri, forradas com duas folhas de papel de filtro umedecidas com cerca de 1 $\mathrm{ml}$ de água destilada, em Câmara de Germinação BOD a $25^{\circ} \mathrm{C}$ sob luz fluorescente branca contínua. Conjuntamente, com o objetivo de complementar as observações obtidas em câmara de germinação, 50 sementes foram submetidas à germinação, sem tratamento pré-germinativo, em tubetes de polietileno contendo substrato agrícola Plantimax, em viveiro com cobertura sombrite $50 \%$, em condições ambientais, e irrigação diária por microaspersão.

Foram realizadas observações diárias, anotandose a data do teste, do início da germinação (determinado pela emergência da raiz primária) bem como o desenvolvimento das plântulas e plantas jovens. Foram descritos, o tipo de morfologia inicial da plântula, o desenvolvimento da raiz, hipocótilo e epicótilo, o tipo e a morfologia dos cotilédones e dos eófilos. Foi considerada como plântula a fase inicial do desenvolvimento pós-seminal, desde a emissão da raiz primária até a completa liberação e expansão dos primeiros eófilos, e planta jovem a fase após o início do surgimento da bifurcação do meristema apical. A altura e diâmetro das plantas jovens em tubetes, foram mensurados aos seis meses após a data do teste $(n=20)$. Para a altura, foi tomada a distância existente entre a borda do tubete e o início do meristema apical do ramo principal, e para o diâmetro do colo foi verificado cerca de $1 \mathrm{~cm}$ abaixo da base da cicatriz cotiledonar.

O padrão de venação foi realizado para folhas jovens, segundo técnicas de clarificação e coloração baseadas em Handro (1967) e montadas entre placas de vidro. A descrição e classificação dos padrões de venação seguiram os tipos básicos definidos por Hickey (1979).

A terminologia adotada na descrição dos frutos e sementes está de acordo com Corner (1976), Barroso 
et al. (1999) e Barroso et al. (2002) e das plântulas e plantas jovens segue Oliveira (1997; 2001). Para as observações e ilustrações do padrão de venação, frutos, sementes e fases iniciais do desenvolvimento, utilizaram-se estereomicroscópio Zeiss Stemi SV 6, provido de câmara clara e os desenhos das plântulas e plantas jovens foram elaborados a olho nu.

\section{Resultados e discussão}

Morfologia dos frutos e sementes - U. lindmanii apresenta fruto apocárpico, constituído de frutíolos livres entre si, estipitados, de forma oblonga ou globosa, carnosos e indeiscentes, assentados sobre receptáculo globoso, pedunculado (Fig. 1A-E). O número de frutíolos dispostos em cacho axilar variou de 3 a 15 $(\mathrm{N}=38)$ e os estípites apresentaram cerca de $1 \mathrm{a}$ $2,5 \mathrm{~cm}$ de comprimento $(\mathrm{N}=38$ ) (Fig. 1C). Os frutos apresentam diferentes colorações de acordo com o estádio de maturação, passando de verdes, amarelos, alaranjados quando imaturos, vermelhos em maturação e pretos quando maduros. Possuem cerca de 0,8 a $1,84 \mathrm{~cm}$ de comprimento (Fig. 2A) e 0,74 a $1,27 \mathrm{~cm}$ de largura (Fig. 2B), pesando aproximadamente 0,4 a $1,66 \mathrm{~g}$ (Fig. 2C) e possuem de 01 a 05 sementes sobrepostas por frutíolo (Fig. 1F e Fig. 2D). As sementes apresentam forma discóide, de inserção lateral no frutíolo, circundadas por faixa mediana disposta no sentido horizontal, formada pela junção dos tegumentos, possuem coloração marrom escura, tegumento ornamentado de aspecto rugoso, rafe circular, hilo e micrópila lateral, endosperma abundante, amiláceo e ruminado, embrião do tipo basal restrito à metade inferior da semente (Fig. 1G-J). Medem cerca de 0,68 a $1,14 \mathrm{~cm}$ de comprimento e 0,64 a $1,07 \mathrm{~cm}$ de largura, pesando cerca de 0,09 a 0,39 g (Fig. 3A-C).

Informações referentes ao período de floração e frutificação das espécies florestais nativas, são fundamentais em programas de colheita de sementes (Piña-Rodrigues 2002). Unonopsis lindmanii apresentou contínua floração e frutificação ao longo do ano, porém, observou-se um pico de floração em novembro e de frutificação em fevereiro. A espécie apresentou frutos de diversas colorações, associadas ao estágio de maturação, sendo considerados maduros na cor vinho à preta (Pott \& Pott 1994). Estes resultados indicam a espécie como importante fonte de recursos para a fauna local. Oliveira \& Paula (2001) citam a ornitocoria como a principal forma de dispersão para $U$. lindmanii, concordando com Pinheiro \& Ribeiro (2001) que descrevem esta síndrome para diversas espécies de anonáceas. $\mathrm{Na}$ área de estudo foi observada uma grande quantidade de frutos maduros no chão, embaixo das árvores, favorecendo uma dispersão secundária zoocórica. Os dados biométricos dos frutíolos e das sementes, contribuem na diferenciação de espécies do mesmo gênero, como $U$. guatterioides e U. stipitata (Carvalho \& Webber 2000). Barroso et al. (1999) ressaltam a importância de estudos de diferentes sementes e frutíolos de espécies de Annonaceae com o objetivo de oferecer dados diferenciais para identificação dos gêneros. A presença de endosperma ruminado causado pela atividade do tegumento da semente, devido a profundas dobras ou invaginações dos tecidos externos, para o interior das sementes é uma característica das sementes da família Annonaceae (Beltrati 1994).

Germinação - Verificou-se 3\% de germinação em câmara de germinação e, $70 \%$ em viveiro de mudas. A plântula é do tipo criptocotiledonar, após a germinação os cotilédones permanecem encerrados no interior dos envoltórios da semente. O processo de germinação iniciou-se lentamente, cerca de 45 dias após a data do teste, pela protusão da raiz primária (Fig. 4A). Aos 60 dias ocorreu o desenvolvimento do hipocótilo, bojudo, glabro de coloração esbranquiçada e da raiz primária, que se apresentou glabra e de coloração amarelada (Fig. 4B). Aos 75 dias, o hipocótilo se alongou, elevando a plântula acima do solo e ocorreu o início do desenvolvimento de raízes laterais (Fig. 4C). Cerca de 80 dias, após a germinação ocorreu a perda do tegumento (Fig. 4D). Nessa fase, observou-se o início do desenvolvimento do epicótilo, o hipocótilo apresentou-se ligeiramente esverdeado na região apical e, bojudo e esbranquiçado, na região basal. Aos 3 meses, a plântula apresentou início do desenvolvimento do $1^{\circ}$ eófilo, de coloração avermelhada, epicótilo desenvolvido de coloração esverdeada, presença de catáfilos no local de inserção dos cotilédones, hipocótilo longo, bojudo e amarelado, raiz primária axial e presença de raízes secundárias (Fig. 4E). Cerca de três meses e meio a plântula apresentou o primeiro par de eófilos bem desenvolvidos, de posição alterna, formado por folhas simples e membranáceas (Fig. 4F). Aos cinco meses (Fig. 5A), a plântula apresentava o segundo par de eófilos, formado por folhas pecioladas de disposição alterna sem estípulas, coloração verde clara em ambas as faces, membranáceas de superfície glabra e lisa. O sistema radicular era axial, constituído por raízes de coloração amarelada com coifa esbranquiçada. As plantas jovens aos seis meses (Fig. 5B), apresentaram ca. de 5,65 cm de altura e 


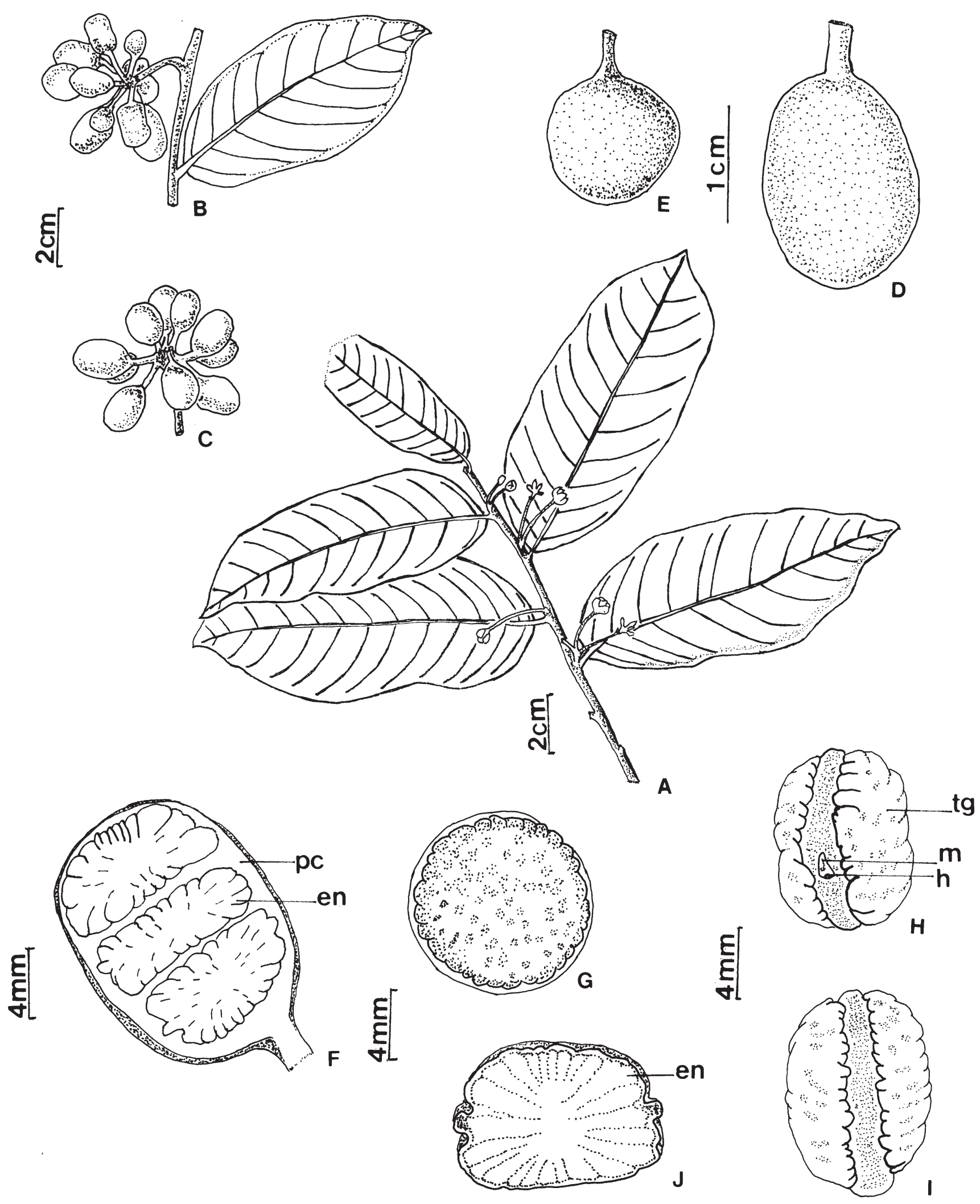

Figura 1. Unonopsis lindmanii Fries. A. Ramo fértil. B-C. Fruto múltiplo com frutíolos livres entre si. D-E. Frutíolos isolados. F. Diagrama da seção longitudinal do fruto. G- I. Aspecto externo da semente madura. J. Corte longitudinal da semente madura. ( $\mathrm{en}=$ endosperma $; \mathrm{h}=$ hilo $; \mathrm{m}=$ micrópila; $\mathrm{pc}=$ pericarpo $; \mathrm{tg}=$ tegumento). 
1,09 mm de diâmetro do caule, início de ramificação do caule a partir do $3^{\circ}$ par de eófilos, meristema apical e primeiro metáfilo de coloração avermelhada.

A baixa taxa germinativa de $3 \%$, obtida para U. lindmanii em câmara de germinação, sugere dependência do fotoperíodo para germinação, já que em viveiro obteve-se bom percentual germinativo, de $70 \%$. A germinação ocorreu de forma lenta e irregular, entre dois a cinco meses. Estes resultados indicam dormência morfológica para a espécie e concordam com Toledo \& Marcos Filho (1977) apud Melo et al. (1998), que descrevem que sementes da família Annonaceae possuem embriões imaturos sendo necessários estudos que possam estabelecer metodologias para uniformizar e acelerar a germinação destas espécies.
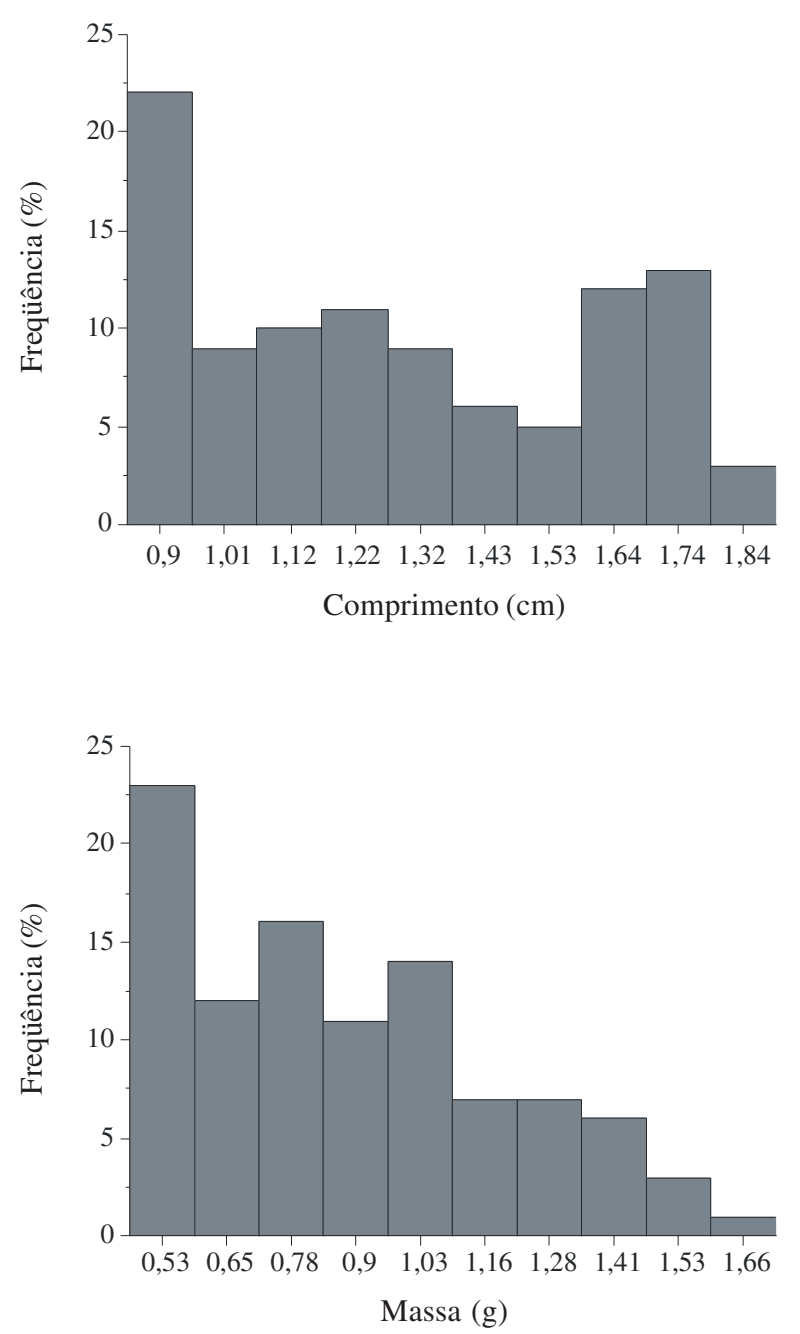

A

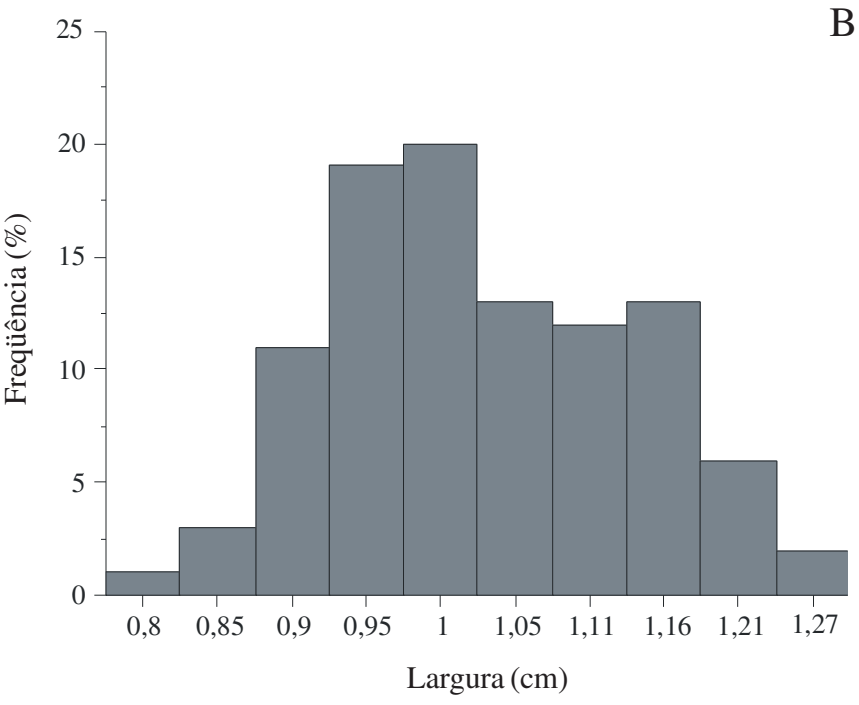

As plântulas de $U$. lindmanii, não apresentaram emissão dos cotilédones, sugerindo serem rudimentares e ocultos no tegumento. No entanto, são necessários estudos anatômicos da semente para comprovar e descrever a morfologia dos cotilédones para a espécie. Baseado na classificação de Oliveira $(1997 ; 2001)$ a morfologia inicial das plântulas, foi considerada do tipo criptocotiledonar - epígea, ou seja, não houve liberação dos cotilédones do tegumento sendo observado alongamento do hipocótilo e elevação do tegumento acima do solo, ao contrário de plântulas hipógeas que apresentam hipocótilo curto e permanecem sob o solo. O tipo durio, proposto por NG (1978) e Miquel (1987) observado em plântulas que expõem seus cotilédones sobre o solo, mas encerrados no interior dos envoltórios da semente, também pode ser utilizado para descrição

C

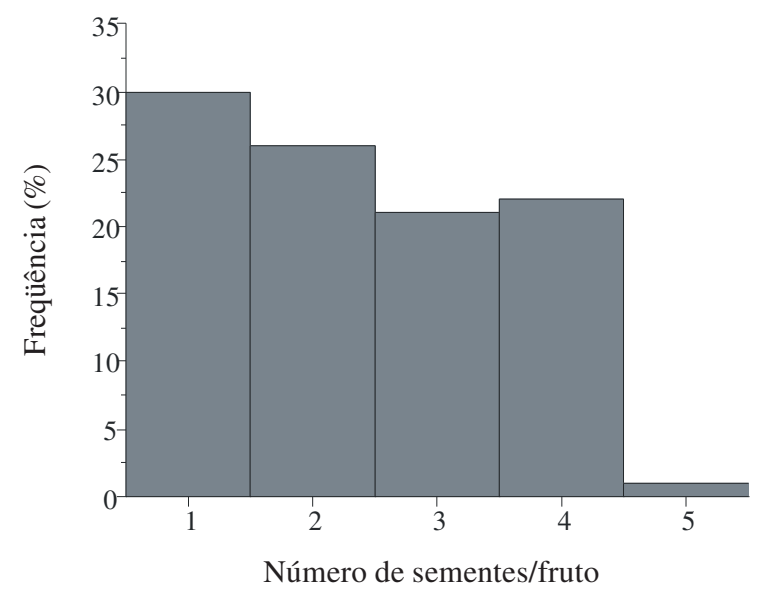

Figura 2. Distribuição de frequência de dimensões morfométricas, massa e número de sementes por frutos de Unonopsis lindmanii Fries.: A. Comprimento. B. Largura. C. Massa. D. Número de sementes por fruto. 
A das plântulas de $U$. lindmanii. O desenvolvimento do
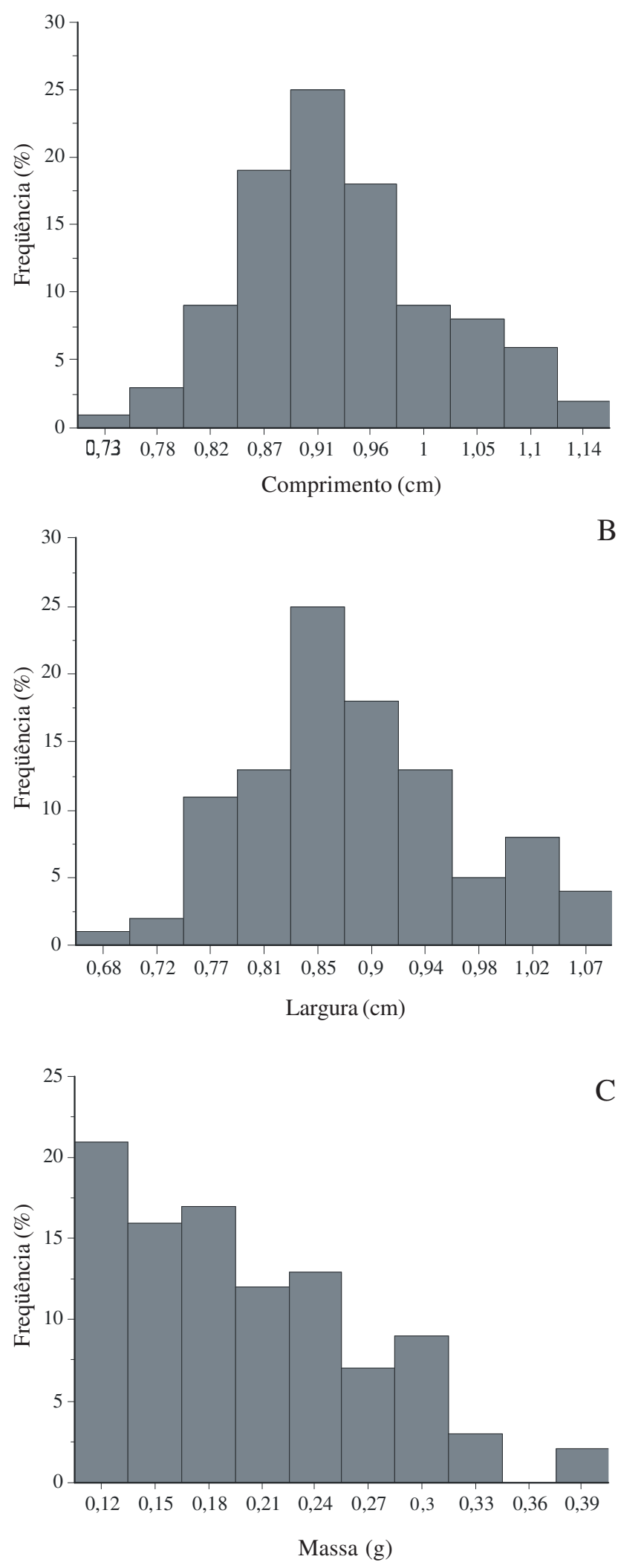

Figura 3. Distribuição de frequência de dimensões morfométricas de sementes de Unonopsis lindmanii Fries.: A. Comprimento. B. Largura. C. Massa. epicótilo, iniciou-se somente após a perda do tegumento, onde é possível observar a presença de catáfilos. Beltrati (1994) define catáfilos, como escamas de cor marrom que sucedem os cotilédones em muitas espécies criptocotiledonares. Os resultados encontrados neste estudo para a morfologia inicial das plântulas de $U$. lindmanii discordam de Ressel et al. (2004) que descrevem para a espécie uma germinação do tipo fanero-epígea-foliácea ao estudarem a morfologia inicial de plântulas de espécies arbóreas da estação ecológica de Panga em Uberlândia, MG.

Padrão de venação - Os primeiros eófilos são simples, alternos, apresentam lâmina e base foliar simétrica, glabra, forma elíptica, ápice acuminado, base ligeiramente aguda e margem inteira. A textura é membranácea, não ocorre presença de glândulas e o pecíolo é normal. A venação é pinada com uma nervura principal simples servindo como origem para a venação das demais ordens. O padrão é camptódromobronquidódromo, ou seja, as nervuras secundárias se juntam em uma série de arcos proeminentes, não terminando na margem (Fig. 6A). A nervura primária é moderada de curso reto não ramificado. Nas nervuras secundárias, $\mathrm{o}$ ângulo de divergência é relativamente reto e uniforme em toda a lâmina (Fig. 6B). A sua espessura é moderada e o seu curso é curvado do tipo abrupto. As terminações das nervuras secundárias nas margens formam ângulo-agudo. As nervuras intersecundárias são do tipo composta. $O$ padrão das nervuras de $3^{\mathrm{a}}$ ordem é do tipo percorrente de curso forquilhado, oblíquas em relação à nervura principal, de organização predominantemente alternada (Fig. 6C). As nervuras $4^{\text {as }}$ e $5^{\text {as }}$ são distintas, tênues, curso casualmente orientado. A venação marginal dispõe-se em laçadas, as vênulas são ramificadas (1 vez) e as aréolas são bem desenvolvidas de arranjo casual e forma irregular (Fig. 6C). O padrão de venação verificado para folhas jovens de $U$. lindmanii neste estudo, confirma os resultados obtidos por Klucking (1986) ao estudar o modelo de venação de U. guatterioides (A.D.C.) R.E.FR. e U. lindmanii, consideradas espécies representativas dentro do gênero Unonopsis.

As características verificadas para $U$. lindmanii neste estudo, contribuem para o conhecimento biológico da espécie e facilitam a identificação das formas juvenis em ambiente natural, e, sugerem com base na relevância para a fauna local a utilização da mesma em projetos de restauração ecológica para as 

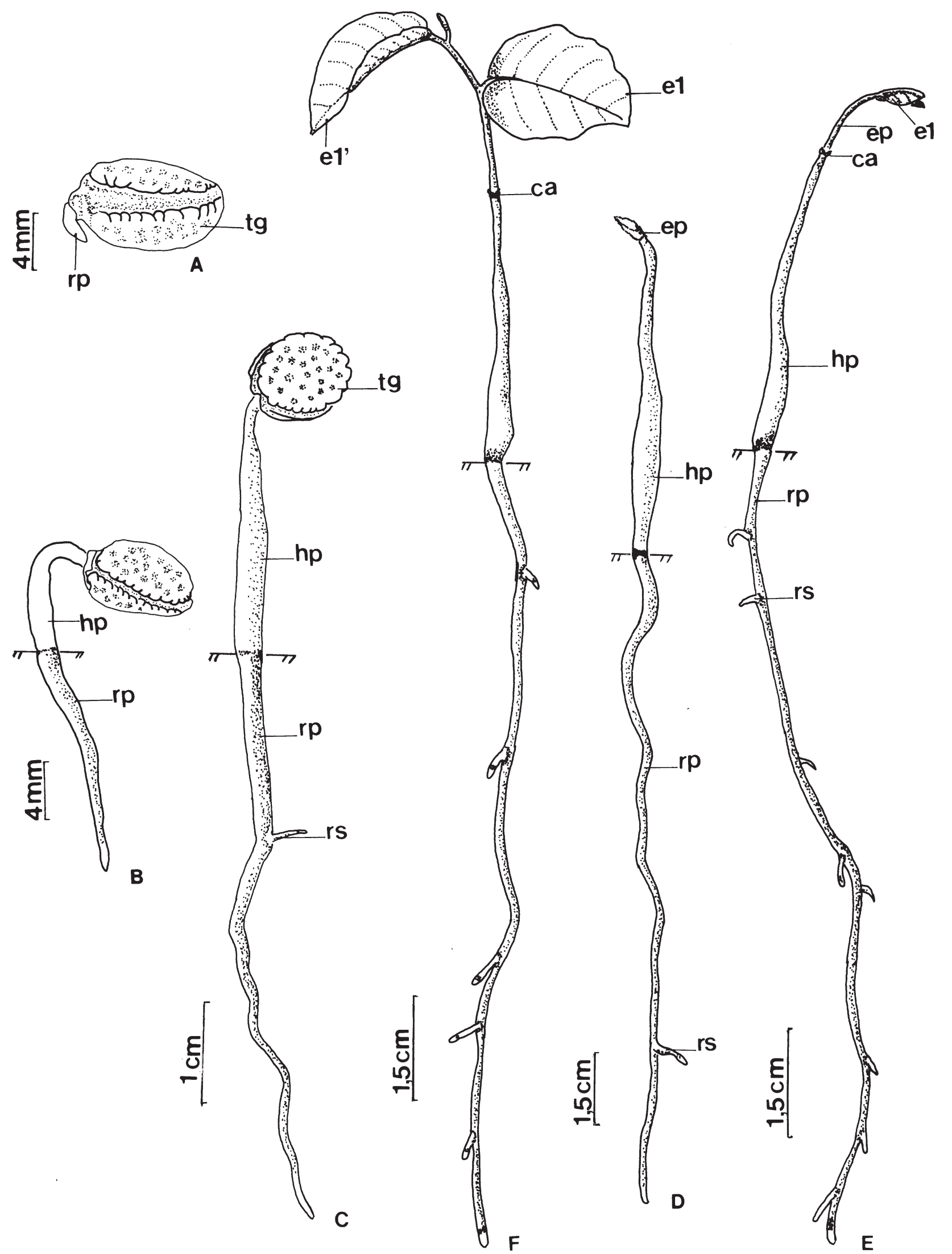

Figura 4. Unonopsis lindmanii Fries. A. Semente embebida e início da ruptura do tegumento. B. Com 60 dias. C. Com 75 dias. D. Com 80 dias. E. Com 90 dias. F. Com 105 dias (tg = tegumento; ep = epicótilo; e1 e e1' = primeiro par de eófilos; ca = catáfilos; hi = hipocótilo; $\mathrm{rp}=$ raiz primária; $\mathrm{rs}=$ raiz secundária $)$. 

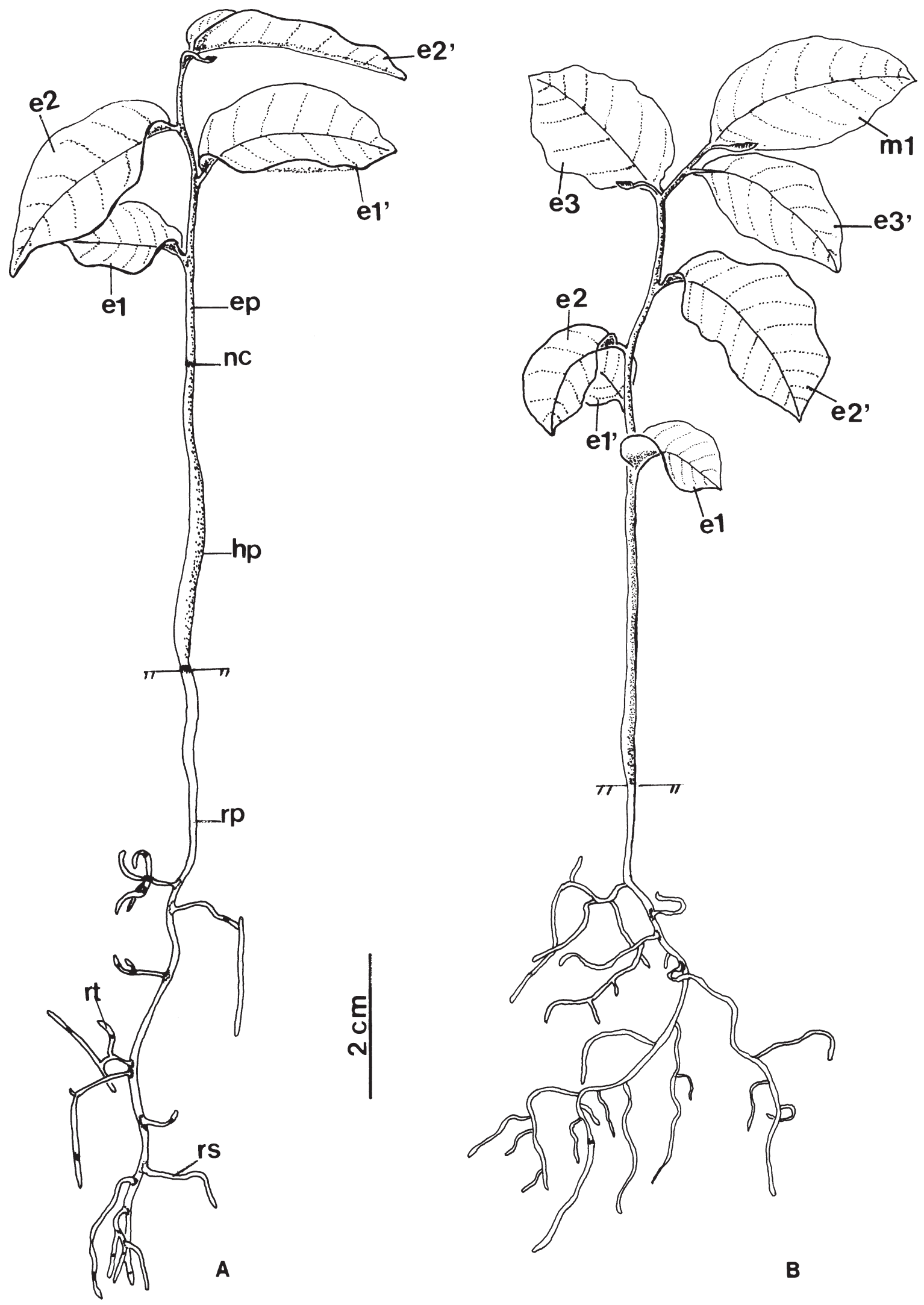

B

Figura 5. Unonopsis lindmanii Fries. A. Plântula com cinco meses. B. Planta jovem com seis meses. (e1-e1' = primeiro par de eófilos; e2-e2' = segundo par de eófilos; e3-e3' = terceiro par de eófilos; ep = epicótilo; $\mathrm{m} 1$ = metáfilo; hi = hipocótilo; nc = nó cotiledonar; $\mathrm{rp}=$ raiz primária; $\mathrm{rs}=$ raiz secundária; $\mathrm{rt}=$ raiz terciária) . 

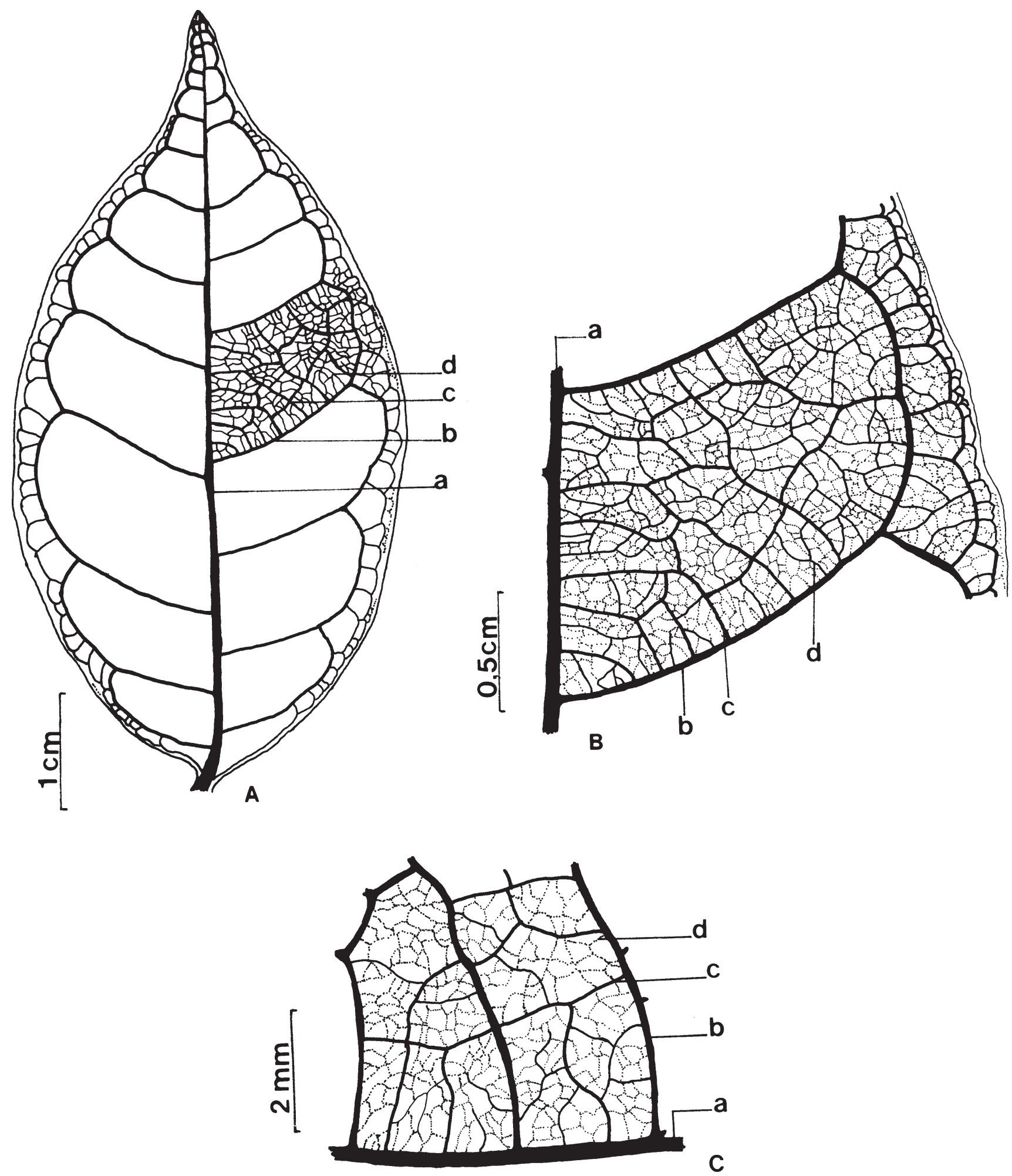

Figura 6. Unonopsis lindmanii Fries. A -B. Padrão geral de venação. C. Venação menor. (a = nervura primária; b = nerv. secundária; $\mathrm{c}=$ nerv. terciária; $\mathrm{d}=$ nerv. quaternária; $\mathrm{e}=$ nerv. quinquenária). 
formações ciliares na região sudoeste do Estado de Mato Grosso do Sul e demais regiões de ocorrência natural da espécie.

\section{Agradecimentos}

À Universidade Estadual de Mato Grosso do Sul (UEMS), Unidade de Ensino de Jardim, por ceder laboratório e viveiro de mudas para a realização deste estudo; a Sra. Elizabete Secomandi, proprietária da Fazenda Nossa Senhora Aparecida, por autorizar a coleta de material botânico em sua propriedade, local denominado "Santuário do Prata", Jardim, MS.

\section{Referências bibliográficas}

Barroso, G.M.; Morrim, M.P.; Peixoto, A.L. \& Ichaso, C.L.F. 1999. Frutos e Sementes. Morfologia Aplicada à Sistemática de Dicotiledôneas. Viçosa, Universidade Federal de Viçosa.

Barroso, G.M.; Peixoto, A.L.; Ichaso, C.L.F.; Guimarães, E.F. \& Costa, C.G. 2002. Sistemática de Angiospermas do Brasil. v.1. $2^{\mathrm{a}}$ ed. Viçosa, Universidade Federal de Viçosa.

Battilani, J.L.; Sremin-Dias, E. \& Souza, A.L.T. 2005. Fitossociologia de um trecho da mata ciliar do rio da Prata, Jardim MS. Acta Botanica Brasilica 19(3): 597-608.

Beltrati, C.M. 1994. Morfologia e Anatomia das sementes. Rio Claro, SP, UNESP, Departamento de Botânica/ Instituto de Biociências.

Cardoso, C.M.V. \& Sajo, M.G. 2004. Vascularização foliar e identificação de espécies de Eugenia L. (Myrtaceae) da bacia hidrográfica do rio Tibagi, PR. Revista Brasileira de Botânica 27(1): 47-54.

Carvalho, R. \& Webber, A.C. 2000. Biologia floral de Unonopsis guatterioides (A.D.C.) R.E. Fr., uma Annonaceae polinizada por Euglossii. Revista Brasileira de Botânica 23(4): 166-174.

Corner, E.J.H. 1976. The seeds of Dicotyledons. v.I., Cambridge, Cambridge University Press.

Cunha, M.C.L. \& Ferreira, R.A. 2003. Aspectos morfológicos da semente e do desenvolvimento da planta jovem de Amburana cearensis (Arr. Cam.) A.C. Smith - cumaru Leguminosae - Papilionoideae. Revista Brasileira de Sementes 25: 89-96.

Felfili, J.M.; Mendonça, R.C.; Walter, B.M.T.; Silva Júnior, M.C.; Nóbrega, M.G.G.; Fagg, C.W.; Sevilha, A.C. \& Silva, M.A. 2001. Flora Fanerogâmica das Matas de Galeria e Ciliares do Brasil Central. Pp. 195-263. In: J.F. Ribeiro; C.E.L. Fonseca \& J.C. Souza-Silva. Cerrado Caracterização e Recuperação de Matas de Galeria. Planaltina, DF, EMBRAPA/Cerrados.

Ferreira, R.A.; Botelho, S.A.; Davide, C.A. \& Malavasi, M.M. 2001. Morfologia de frutos, sementes, plântulas e plantas jovens de Dimorphandra mollis Benth. - faveira (Leguminosae-Caesalpiniodeae). Revista Brasileira de Botânica 24(3): 303-309.
Handro, W. 1967. Contribuição ao estudo da venação e anatomia foliar das Amarantáceas dos cerrados. II Gênero Pfaffia. Anais da Academia Brasileira de Ciências 39(3-4): 495-506.

Hickey, L.J. 1979. A revised classification of the architecture of dicotyledonous leaves. Pp. 25-40. In: C.L. Metcalfe \& R. Chalk. Anatomy of the dicotyledons. Systematic anatomy of leaf and stem, with a brief history of the subject. 2. ed. Oxford, Clarendon Press, v.1.

Johansen, D.A. 1940. Plant microtechnique. New York, McGraw-Hill.

Klucking, E.P. 1986. Leaf Venation Patterns - Annonaceae. v.1. Berlin-Stuttgart, J. Cramer.

Melo, M.G.G.; Mendonça, M.S. \& Mendes, A.M. 2004. Análise morfológica de sementes, germinação e plântulas de jatobá (Hymenaea intermedia Ducke var. adenotricha (Ducke) Lee \& Lang.) LeguminosaeCaesalpinoideae. Acta Amazônica 34(1): 9-14.

Melo, J.T.; Silva, J.A.; Torres, R.A.A.; Silveira, C.E.S. \& Caldas, L.S. 1998. Coleta, propagação e desenvolvimento inicial de espécies do Cerrado. Pp. 195-243. In: S.M. Sano \& S.P. Almeida. Cerrado - ambiente e flora. Planaltina, DF, EMBRAPA/CPAC.

Miguel, S. 1987. Morphologie fonctionelle de plantules d'especes forestières du Gabon. Bulletin du Museum National d'Histoire Naturelle, Section B. Adansonia, Botanique Phytochimie 9: 101-121.

NG, F.S.P. 1978. Strategies of establishment in Malayan forest trees. Pp. 129-162. In: P.B. Tomlinson \& M.H. Zimmermann. Tropical trees as living systems. Cambridge, University Press.

Oliveira, D.M.T. 1997. Análise Morfológica Comparativa de Frutos, Sementes, Plântulas e Plantas Jovens de 30 espécies Arbóreas de Fabaceae Ocorrentes no Estado de São Paulo. Tese de Doutorado. UNESP-RC.

Oliveira. D.M.T. 2001. Morfologia comparada de plântulas e plantas jovens de leguminosas em arbóreas nativas: espécies de Phaseoleae, Sophoreae, Swartzieae e Tephrosieae. Revista Brasileira de Botânica 24(1): 85-97.

Oliveira, P.E.A.M. \& Paula, F.R. 2001. Fenologia e biologia reprodutiva de plantas de mata de galeria. Pp. 303-332. In: J.F. Ribeiro; C.E.L. Fonseca \& J.C. Souza-Silva. Cerrado - Caracterização e Recuperação de Matas de Galeria. Planaltina, DF, EMBRAPA/Cerrados.

Oliveira Filho, A.T. \& Ratter, J. 2000. Padrões Florísticos das Matas Ciliares da Região do Cerrado e a Evolução das Paisagens do Brasil Central durante o Quaternário Tardio. Pp. 73-89. In: R.R. Rodrigues \& H.F. Leitão Filho. 2000. Matas Ciliares - Conservação e Recuperação. São Paulo, EDUSP/Editora da Universidade de São Paulo.

Pinã-Rodrigues, F.C.M. 2002. Guia prático para a colheita e manejo de sementes florestais tropicais. Rio de Janeiro, IDACO.

Pinheiro, F. \& Ribeiro, J.F. 2001. Síndromes de dispersão de sementes em Matas de Galeria do Distrito Federal. Pp. 335-375. In: J.F. Ribeiro; C.E.L. Fonseca \& J.C. SouzaSilva. 2001. Cerrado - Caracterização e Recuperação de Matas de Galeria. Planaltina, DF, EMBRAPA/Cerrados.

Pontes, A.F.; Barbosa, M.R.V. \& Maas, P.J.M. 2004. Flora Paraibana: Annonaceae Juss. Acta Botanica Brasilica 18(2): 281-293. 
Pott, A. \& Pott, V.J. 1994. Plants of Pantanal. Corumbá, MS, Empresa Brasileira de Pesquisa Agropecuária, Centro de Pesquisa Agropecuária do Pantanal.

Pott, A. \& Pott, V.J. 2003. Espécies de Fragmentos Florestais em Mato Grosso do Sul. Pp. 26-52. In: R.B. Costa. Fragmentação Florestal e Alternativas de Desenvolvimento Rural na Região Centro-Oeste. Campo Grande, MS, UCDB.

Ressel, K.; Guilherme, F.A.G.; Schiavini, I. \& Oliveira, P.E. 2004. Ecologia morfofuncional de plântulas de espécies arbóreas da Estação Ecológica do Panga, Uberlândia, Minas Gerais. Revista Brasileira de Botânica 27(2): 311-323

Romagnolo, M.B. \& Souza, M.C. 2000. Análise florística e estrutural de florestas ripárias do alto Rio Paraná, Taquaruçu, MS. Acta Botanica Brasilica 14(2): 163-174.
Silva, D.B.; Silva, J.A.; Junqueira, N.T.V. \& Andrade, L.R.M. 2001. Frutas do Cerrado. EMBRAPA/Cerrados. Planaltina, DF.

Silva Júnior, M.C.; Santos, G.C.; Nogueira, P.E.; Munhoz, C.B.R. \& Ramos, A.E. 2005. 100 Árvores do Cerrado Guia de Campo. Brasília, DF, Rede de Sementes do Cerrado.

Tabarelli, M.; Mantovani, W. \& Peres, C.A. 1999. Effects of habitat fragmentation on plant guild structure in the montane Atlantic forest of southeastern Brazil. Biological Conservation 91: 119-127.

Toniato, M.T.Z. \& Oliveira Filho A.T. 2004. Variations in tree community composition and structure in a fragment of tropical semideciduous Forest in southeastern Brazil related to different human disturbance histories. Forest Ecology and Management 198: 319-339. 